SEEN

\title{
ACROSTART: A retrospective study of the time to achieve hormonal control with lanreotide Autogel treatment in Spanish patients with acromegaly
}

\author{
Cristina Álvarez-Escoláa,*, Eva María Venegas-Moreno ${ }^{\mathrm{b}}$, \\ Juan Antonio García-Arnés ${ }^{c}$, Concepción Blanco-Carrera ${ }^{d}$, \\ Mónica Marazuela-Azpiroz ${ }^{e}$, María Ángeles Gálvez-Moreno ${ }^{f}$, \\ Edelmiro Menéndez-Torre ${ }^{g}$, Javier Aller-Pardo ${ }^{h}$, Isabel Salinas-Vert ${ }^{i}$, \\ Eugenia Resmini ${ }^{\mathrm{j}, \mathrm{k}}$, Elena María Torres-Vela', María Ángeles Gonzalo-Redondo ${ }^{\mathrm{m}}$, \\ Ricardo Vílchez-Joya ${ }^{n}$, María Paz de Miguel-Novoa ${ }^{\circ}$, \\ Irene Halperín-Rabinovich ${ }^{\mathrm{p}}$, Concepción Páramo-Fernández ${ }^{\mathrm{q}}$, \\ Guillermo de la Cruz-Sugranyes ${ }^{r}$, Aude Houchard ${ }^{s}$, Antonio Miguel Picó-Alfonso ${ }^{t}$, \\ on behalf of the ACROSTART Study Group
}

\footnotetext{
${ }^{a}$ Endocrinology and Nutrition Department, Hospital Universitario La Paz, Madrid, Spain

${ }^{\mathrm{b}}$ Endocrinology Department, Hospital Universitario Virgen del Rocío, Sevilla, Spain

' Endocrinology and Nutrition Service, Hospital Regional Universitario de Málaga, Málaga, Spain

d Endocrinology Department, Hospital Universitario Príncipe de Asturias, Alcalá de Henares, Madrid, Spain

e Endocrinology Department, Hospital Universitario de La Princesa, Universidad Autónoma de Madrid, Instituto Princesa, Madrid, Spain

f Endocrinology Service, Hospital Universitario Reina Sofía de Córdoba, Córdoba, Spain

s Endocrinology and Nutrition Department, Hospital Universitario Central de Asturias, Oviedo, Spain

h Endocrinology Department, Neuroendocrinology \& Endocrine Oncology Unit, Hospital Universitario Puerta de Hierro, Majadahonda, Madrid, Spain

'Endocrinology and Nutrition Department, Hospital Universitario Germans Trias i Pujol, Badalona, Barcelona, Spain

j Hospital Sant Pau, Centro de Investigación Biomédica en Red de Enfermedades Raras (CIBER-ER, Unidad 747), IIB-Sant Pau,

Barcelona, Spain

k Universitat Autònoma de Barcelona, Barcelona, Spain

' Endocrinology and Nutrition, Complejo Hospitalario Universitario, Granada, Spain

m Endocrinology and Nutrition Department, Fundación Jiménez Díaz, Madrid, Spain

${ }^{\mathrm{n}}$ Endocrinology and Nutrition Service, Hospital Universitario Virgen de las Nieves, Granada, Spain

${ }^{\circ}$ Endocrinology Department, Hospital Clínico San Carlos, Universidad Complutense de Madrid, Madrid, Spain

${ }^{\mathrm{P}}$ Endocrinology Department, Hospital Clínic, Universitat de Barcelona, Barcelona, Spain

${ }^{\mathrm{q}}$ Endocrinology and Nutrition Department, Complejo Hospitalario Xeral-Cies de Vigo, Vigo, Pontevedra, Spain
}

\footnotetext{
* Corresponding author.

E-mail address: escola.cristina@gmail.com (C. Álvarez-Escolá).

$\diamond$ Study investigators are all listed as authors.
} 
${ }^{r}$ Medical Department, IPSEN PHARMA S.A., L'Hospitalet de Llobregat, Barcelona, Spain

s Statistics Department, IPSEN PHARMA, Boulogne-Billancourt, France

${ }^{\mathrm{t}}$ Endocrinology Department, Hospital General Universitario de Alicante-ISABIAL-FISABIO, Alicante, Spain

Received 3 July 2018; accepted 6 December 2018

Available online 14 February 2019

\section{KEYWORDS \\ Acromegaly; \\ Lanreotide; \\ Somatuline Autogel; \\ Dosage regimens; \\ Growth hormone \\ (GH); \\ Insulin-like growth \\ factor (IGF-I)}

\begin{abstract}
Objectives: The ACROSTART study was intended to determine the time to achieve normalization of GH and IGF-I levels in responding patients with acromegaly administered different dosage regimens of lanreotide Autogel (Somatuline ${ }^{\oplus}$ Autogel $^{\oplus}$ ).

Methods: From March 2013 to October 2013, clinical data from 57 patients from 17 Spanish hospitals with active acromegaly treated with lanreotide for $\geq 4$ months who achieved hormonal control (GH levels $<2.5 \mathrm{ng} / \mathrm{ml}$ and/or normalized IGF-I levels in $\geq 2$ measurements) were analyzed. The primary objective was to determine the time from start of lanreotide treatment to hormonal normalization.

Results: Median patient age was 64 years, 21 patients were male, 39 patients had undergone surgery, and 14 patients had received radiotherapy. Median hormonal values at start of lanreotide treatment were: $\mathrm{GH}, 2.6 \mathrm{ng} / \mathrm{ml}$; IGF-I, $1.6 \times$ ULN. The most common starting dose of lanreotide was $120 \mathrm{mg}$ (29 patients). The main initial regimens were $60 \mathrm{mg} / 4$ weeks $(n=13)$, $90 \mathrm{mg} / 4$ weeks $(n=6), 120 \mathrm{mg} / 4$ weeks $(n=13), 120 \mathrm{mg} / 6$ weeks $(n=6)$, and $120 \mathrm{mg} / 8$ weeks $(n=9)$. An initial treatment regimen with a long interval ( $\geq 6$ weeks) was administered in 25 patients. Mean duration of lanreotide treatment was 68 months (7-205). Median time to achieve hormonal control was 4.9 months. Injections were managed without healthcare assistance in 13 patients. Median number of visits to endocrinologists until hormonal control was achieved was 3. Fifty-one patients were "satisfied" / "very satisfied" with treatment and 49 patients did not miss any dose.

Conclusions: Real-life treatment with lanreotide Autogel resulted in early hormonal control in responding patients, with high treatment adherence and satisfaction despite disparity in starting doses and dosing intervals.

(c) 2019 SEEN y SED. Published by Elsevier España, S.L.U. All rights reserved.
\end{abstract}

\author{
PALABRAS CLAVE \\ Acromegalia; \\ Lanreótida; \\ Somatulina Autogel; \\ Patrones de \\ dosificación; \\ Hormona del \\ crecimiento $(\mathrm{GH})$; \\ Factor de \\ crecimiento de la \\ insulina (IGF-I)
}

\section{ACROSTART: Estudio retrospectivo del período de tiempo para lograr el control hormonal con lanreótida Autogel en pacientes con acromegalia en la práctica clínica española}

\section{Resumen}

Objetivos: El objetivo del estudio ACROSTART era determinar el período de tiempo para lograr la normalización hormonal (GH e IGF-I) en pacientes con acromegalia respondedores al tratamiento considerando los regímenes de lanreótida Autogel (Somatuline ${ }^{\circledast}$ Autogel $^{\circledR}$ ) utilizados en la práctica clínica.

Métodos: Desde marzo de 2013 hasta octubre de 2013, en 17 hospitales españoles se analizaron los datos clínicos de 57 pacientes con acromegalia activa tratados con lanreótida durante $\geq 4$ meses que lograron control hormonal (niveles de $\mathrm{GH}<2,5 \mathrm{ng} / \mathrm{ml}$ y/o IGF-I normalizado en $\geq 2$ evaluaciones). El objetivo principal fue determinar el período de tiempo desde el inicio del tratamiento con lanreótida hasta la normalización hormonal.

Resultados: La mediana de edad de los pacientes fue 64 años, 21 pacientes eran hombres, 39 pacientes habían recibido cirugía, 14 pacientes habían recibido radioterapia. Los valores hormonales medianos al inicio del tratamiento con lanreótida fueron GH: 2,6 ng/ml, IGF-I: $1,6 \times$ LSN. La dosis inicial más frecuente de lanreótida fue de $120 \mathrm{mg}$ (29 pacientes). Los principales regímenes iniciales fueron $60 \mathrm{mg} / 4$ semanas $(n=13), 90 \mathrm{mg} / 4$ semanas $(n=6), 120 \mathrm{mg} /$ 
4 semanas $(n=13), 120 \mathrm{mg} / 6$ semanas $(n=6), 120 \mathrm{mg} / 8$ semanas $(n=9)$. Se administró un régimen de intervalo prolongado ( $\geq 6$ semanas) en 25 pacientes. La duración media del tratamiento con lanreótida fue de 68 meses (7-205). El tiempo medio hasta lograr el control hormonal fue de 4,9 meses. Las inyecciones se manejaron sin asistencia médica en 13 pacientes. La mediana del número de visitas al endocrinólogo hasta el control hormonal fue 3 . Cincuenta y un pacientes estaban "satisfechos" / "muy satisfechos" con el tratamiento y 49 pacientes no olvidaron ninguna dosis.

Conclusiones: El tratamiento en la vida real con lanreótida Autogel condujo a un control hormonal temprano en pacientes que respondieron, con una alta adherencia al tratamiento y satisfacción con el tratamiento, a pesar de la disparidad de las dosis iniciales y los intervalos de dosificación.

(c) 2019 SEEN y SED. Publicado por Elsevier España, S.L.U. Todos los derechos reservados.

\section{Introduction}

Acromegaly is a rare chronic endocrine disease, characterized by enhanced growth hormone $(\mathrm{GH})$ secretion and elevated insulin-like growth factor-I (IGF-I) levels; the most frequent cause of which is a benign pituitary adenoma. ${ }^{1}$ Persistently high levels of GH and IGF-I cause significant mortality and morbidity, mainly due to cardiovascular and respiratory complications. ${ }^{2}$ Therefore, control of GH and IGF-I secretion is decisive in improving survival. ${ }^{3}$

The current goals of acromegaly treatment are to eliminate the tumor or, if not possible, to reduce or control its growth, normalization of GH and IGF-I levels and prevention and adequate management of comorbidities. ${ }^{2}$ Therapeutic management strategies include surgery, radiotherapy and medical treatment. Pharmacological therapy plays a key role in managing patients with acromegaly when surgery or radiotherapy are not an option, and consists of somatostatin analogs (SSAs), lanreotide, octreotide, and pasireotide, as well as dopamine agonists and $\mathrm{GH}$ receptor antagonists. SSAs have become the pillar of acromegaly medical therapy in patients who are unsuitable for, or refuse surgery, after failure of surgical treatment, or as primary treatment in selected cases. ${ }^{4}$

Initial recommended doses of the SSA lanreotide Autogel (Somatuline $^{\circledR}$ Autogel $^{\circledR}$, Ipsen Pharma) are 60, 90 and $120 \mathrm{mg}$ administered every 28 days. The long-term safety and efficacy of lanreotide Autogel in patients with acromegaly has been analyzed in previous studies. In a large cohort of acromegalic patients, sustained control of $\mathrm{GH}$ and IGF-I levels was obtained with lanreotide Autogel, with approximately $50 \%$ of patients obtaining $\mathrm{GH}$ levels $<2.5 \mathrm{ng} / \mathrm{ml}$ and/or normalized IGF-I levels by week 16 of treatment. ${ }^{5}$ Experience in studies evaluating the use of lanreotide indicated that a longer dosage interval could be used in well controlled patients with similar efficacy, ${ }^{6-9}$ thus suggesting that extending the dosing interval to 42 and 56 days may be a common therapeutic strategy. The starting dose for lanreotide Autogel prescribed in Spain may differ from prescribing recommendations. ${ }^{8}$

In view of the above, this study (ACROSTART) was proposed to determine the time to achieve hormonal normalization control considering the initial doses and dosage intervals of lanreotide Autogel commonly used in clinical practice.

\section{Material and methods}

\section{Study design}

ACROSTART was a multicenter, non-interventional, retrospective, post-authorization study performed in adult patients with active acromegaly conducted at 17 centers in Spain. The centers who participated in the study were experienced in the management of acromegaly. Responder patients whose acromegaly was managed with lanreotide Autogel were sequentially proposed from 08 March to 31 October 2013 to participate in the study. As this was a noninterventional study, the decision to prescribe lanreotide Autogel was made prior to and independently from the patient's enrolment into the study and it was prescribed as routinely at each center. The dosing regimens to be administered were entirely at the discretion of the treating physician.

Study included adults ( $\geq 18$ years) with active acromegaly (GH levels $\geq 2.5 \mathrm{ng} / \mathrm{ml}$ and/or non-normalized IGF-I levels) who had been treated with lanreotide Autogel monotherapy for at least 4 months and achieved $\mathrm{GH}$ levels $<2.5 \mathrm{ng} / \mathrm{ml}$ and/or normalized IGF-I levels on at least two consecutive evaluations (responder patients). The measurements must have been done with at least a 4-month interval prior to the study. Patients whose clinical records lacked information regarding the date and initial dose of lanreotide Autogel and the first hormonal response available were excluded. Patients that did not achieve hormone control or achieved only partial hormonal control were excluded from the study. The study included both patients who had undergone prior surgery or radiotherapy or who were treatment naive. Patients who had received prior treatment with another SSA or other acromegaly drugs were also allowed to be included in the study. All patients provided written informed consent.

To guarantee the retrospective and observational nature of the study, the information was collected retrospectively from the patient's clinical history chart and no additional diagnostic or therapeutic interventions were performed. Approval was obtained from the appropriate regulatory bodies, prior to study initiation. This study adhered to all local regulatory requirements applicable to non-interventional studies. Before initiating the study, each investigator/institution had obtained written and 
dated approval/favorable opinion from the Independent Ethics Committee (IEC)/Institutional Review Board (IRB). The study was performed in accordance with the requirements expressed in the Declaration of Helsinki, as well as Spanish legislation concerning observational studies. This study was funded by Ipsen Pharma S.A., Spain.

\section{Assessments}

The following data were collected from patients' clinical history, when available: sociodemographic and sociofamiliar data, data on the diagnosis of acromegaly, data related to the treatment of acromegaly, changes in comorbidities (diabetes, carpal tunnel syndrome, sleep apnea and arterial hypertension) and concomitant medications for arterial hypertension and diabetes, data related to tumor control. Data related to patient satisfaction (at the time that the patient provided informed signed consent, the investigator asked a direct question to the patient about satisfaction with 3 possible answers [Very satisfied, satisfied, not at all satisfied]) and adherence to treatment (determined by the number of omitted doses and by patients' continuation of the treatment at the end of the study), and clinical and economic aspects (use of healthcare resources: endocrinologist and nurses visits, laboratory and image testing, days of absenteeism [days of absenteeism were defined as the total sum of visits to doctor, hospital nurse or outpatient nurse. Each visit was considered as one day of absenteeism]) until obtaining control of the disease.

The levels of GH and IGF-I were noted at the following times: at diagnosis, presurgically, after surgical treatment, start of treatment with lanreotide Autogel and when these levels were normalized during treatment with lanreotide Autogel. As this is a retrospective, non-interventional study, hormone levels were measured as per clinical practice at each center; the methods were not standardized across different centers. In addition, the frequency of study visits, biochemical testing, and radiological evaluation as well as the methods used were determined by the endocrinologist in charge.

As this was a non-interventional study in which lanreotide Autogel was to be administered and managed within routine medical care, adverse event $(\mathrm{AE})$ reporting followed regulations related to spontaneous cases. Investigators were asked to report only related AEs (non serious and serious) to the safety department of the manufacturer of lanreotide Autogel if this had not been already done at the time of onset of the $A E$, using the usual process for such reactions.

\section{Objectives}

The primary objective was to determine the time to achieve hormonal control (defined as GH levels $<2.5 \mathrm{ng} / \mathrm{ml}$ and/or normalized IGF-I on at least 2 different evaluations) considering the starting dose and dosage intervals of lanreotide Autogel.

Secondary objectives included collecting clinical data on patients according to initial treatment regimen, including changes in co-morbidities, determining the ability of the self-inject either by the patient or a relative, the use of healthcare resources until obtaining hormonal control, assessing the effectiveness of lanreotide Autogel in controlling tumor size, evaluating patients' general satisfaction with lanreotide Autogel therapy, and assessing patients' adherence to lanreotide Autogel therapy.

\section{Sample size}

The sample size calculation was based on the number of patients that, when included in the study, would provide sufficient information to determine the primary study objective. The long-term safety and efficacy of lanreotide Autogel in patients with acromegaly has been analyzed in previous studies. Specifically, the study by Melmed et al. ${ }^{5}$ in a large cohort of unselected patients showed sustained control of GH and IGF-I levels with lanreotide Autogel, with approximately $50 \%$ of patients obtaining $\mathrm{GH}$ levels $<2.5 \mathrm{ng} / \mathrm{ml}$ and/or normalized IGF-I levels in week 16 of treatment with the following doses: $60,90,120 \mathrm{mg}$ every 28 days. This level of control was also observed with an injection frequency every 8 weeks. ${ }^{8}$ Thus, the sample size was calculated so that the group of patients included in the ACROSTART study permitted an estimation of an assumed stabilization of $50 \%$ of patients at 16 weeks, with a precision of \pm 0.14 percentage units. Assuming a 2-sided alpha risk of 0.05 (type I error), and a percentage of loss due to incomplete data, inconsistencies, etc. of no more than $20 \%$, a total of 59 patients were to be included.

\section{Statistical analysis}

The primary analysis set (PAS) consisted of all screened patients who had taken lanreotide Autogel for at least 4 months, with date of hormone normalization recorded and without major protocol deviations. The primary and secondary objectives analyses were performed on the PAS population. The primary objective was the time to hormonal normalization on at least 2 different evaluations considering the commonly used starting doses and dosage intervals of lanreotide Autogel. Hormonal control was considered to have been achieved at the second evaluation and this time point was used for statistical analyses. The primary and secondary endpoints were reported using descriptive quantitative summary statistics. To determine the effectiveness of lanreotide Autogel in controlling tumor size, descriptive statistics of tumor volume and percentage tumor shrinkage were obtained, as follows:

$\%$ tumor shrinkage (at the most recent evaluations during treatment with lanreotide Autogel with regards to the start of treatment $)=[$ (Maximum tumor volume at the most recent evaluations during treatment with lanreotide Autogel - Maximum tumor volume at the start of treatment)/(Maximum tumor volume at the start of treatment) ${ }^{*} 100$.

\section{Results}

\section{Patients}

Sixty-two patients were screened from 08 March to 31 October 2013. Five patients were excluded from the analysis 
Table 1 Patient demographics and disease characteristics.

\begin{tabular}{|c|c|c|c|c|c|c|}
\hline & $\begin{array}{l}\text { PAS } \\
N=57\end{array}$ & $\begin{array}{l}60 \mathrm{mg} / 4 \text { weeks } \\
n=13\end{array}$ & $\begin{array}{l}90 \mathrm{mg} / 4 \text { weeks } \\
n=6\end{array}$ & $\begin{array}{l}120 \mathrm{mg} / 4 \text { weeks } \\
n=13\end{array}$ & $\begin{array}{l}120 \mathrm{mg} / 6 \text { weeks } \\
n=6\end{array}$ & $\begin{array}{l}120 \mathrm{mg} / 8 \text { weeks } \\
n=9\end{array}$ \\
\hline Male, $n(\%)$ & $21(36.8)$ & $4(30.8)$ & $1(16.7)$ & $6(46.2)$ & $3(50.0)$ & $3(33.3)$ \\
\hline $\begin{array}{l}\text { Patient able to } \\
\text { self-inject, } n(\%)\end{array}$ & $8(14.0)$ & $2(15.4)$ & $2(33.3)$ & $2(15.4)$ & 0 & 0 \\
\hline $\begin{array}{l}\text { Injection by family } \\
\text { member/relative, } \\
n(\%)\end{array}$ & $5(8.8)$ & $1(7.7)$ & 0 & $1(7.7)$ & $1(16.7)$ & 0 \\
\hline $\begin{array}{l}\text { Injection by } \\
\text { healthcare staff, } n \\
(\%)\end{array}$ & $44(77.2)$ & $10(76.9)$ & $4(66.7)$ & $10(76.9)$ & $5(83.3)$ & $9(100)$ \\
\hline $\begin{array}{l}\text { Median age, years } \\
\text { (range) }\end{array}$ & $64(23-90)$ & $67(27-83)$ & $51.5(30-77)$ & $57(32-88)$ & $73(23-90)$ & $70(37-83)$ \\
\hline $\begin{array}{l}\text { Median time since } \\
\text { diagnosis until } \\
\text { study entry, } \\
\text { months (range) }\end{array}$ & $\begin{array}{l}103.5 \\
(8.1-325.5)\end{array}$ & $\begin{array}{l}100.7 \\
(14.6-285.0)\end{array}$ & $\begin{array}{l}103.7 \\
(8.1-128.4)\end{array}$ & $\begin{array}{l}129.9 \\
(19.3-284.2)\end{array}$ & $\begin{array}{l}170.1 \\
(17.9-325.5)\end{array}$ & $\begin{array}{l}120.8 \\
(41.6-218.6)\end{array}$ \\
\hline \multicolumn{7}{|c|}{ Type of adenoma, $n(\%)$} \\
\hline Microadenoma & $22(38.6)$ & $8(61.5)$ & $2(33.3)$ & $6(46.2)$ & 0 & $2(22.2)$ \\
\hline Macroadenoma & $35(61.4)$ & $5(38.5)$ & $4(66.7)$ & $7(53.8)$ & $6(100)$ & $7(77.8)$ \\
\hline \multicolumn{7}{|c|}{ Prior treatment, $n(\%)$} \\
\hline Surgery & $39(68.4)$ & $8(61.5)$ & $5(83.3)$ & $7(53.8)$ & $4(66.7)$ & $7(77.8)$ \\
\hline Radiotherapy & $14(24.6)$ & $2(15.4)$ & $2(33.3)$ & $6(46.2)$ & $1(16.7)$ & $1(11.1)$ \\
\hline \multicolumn{7}{|c|}{ Hormonal values at start of lanreotide Autogel treatment } \\
\hline $\begin{array}{l}\mathrm{GH}, \mathrm{ng} / \mathrm{ml} \text {, median } \\
\text { (range) }\end{array}$ & $\begin{array}{l}2.6 \\
(0.2-48.2)\end{array}$ & $\begin{array}{l}2.65 \\
(0.2-20.5)\end{array}$ & $\begin{array}{l}3.90 \\
(3.2-48.2)\end{array}$ & $\begin{array}{l}2.52 \\
(1.1-37.5)\end{array}$ & $\begin{array}{l}1.58 \\
(0.5-3.7)\end{array}$ & $\begin{array}{l}2.84 \\
(0.9-8.0)\end{array}$ \\
\hline $\begin{array}{l}\text { IGF-I (×ULN), } \\
\text { median (range) }\end{array}$ & $\begin{array}{l}1.6 \\
(1.0-4.4)\end{array}$ & $\begin{array}{l}1.6 \\
(1.1-3.2)\end{array}$ & $\begin{array}{l}4.0 \\
(1.1-4.4)\end{array}$ & $\begin{array}{l}1.4 \\
(1.0-3.4)\end{array}$ & $\begin{array}{l}1.1 \\
(1.0-1.9)\end{array}$ & $\begin{array}{l}1.4 \\
(1.0-2.2)\end{array}$ \\
\hline
\end{tabular}

Microadenoma $\leq 10 \mathrm{~mm}$, macroadenoma $>10 \mathrm{~mm}$.

PAS, primary analysis set; ULN, upper limit of normal.

because they underwent surgery or received radiotherapy after the initiation of treatment with lanreotide Autogel but before achieving hormonal control. The PAS population consisted of 57 patients with a median age of 64 years (range 23-90) at study entry and a median age at diagnosis of 51 years (range 13-77). Demographic characteristics are shown in Table 1 . At study entry there were 5 patients $\geq 80$ years old (80 years $n=1$, diagnosed at 53 years with extrasellar macroadenoma; 83 years $n=2$, both diagnosed at 65 years, both with microadenoma; 88 years $n=1$, diagnosed at 77 years with microadenoma; and 90 years $n=1$, diagnosed at 72 years with intrasellar macroadenoma); 4 were females.

Most patients $(68.4 \%)$ began treatment because they were not able to obtain adequate disease control with surgery. The median time since the last surgery to start treatment with lanreotide Autogel was 33.9 months (range, 2.3-191.0 months). There were $5(12.8 \%)$ patients that had more than one surgery. Presurgery and post-surgery hormone data are found in Table 2 . There were 14 patients (24.6\%) that underwent radiotherapy. The median time since the last radiotherapy to start treatment with lanreotide Autogel was 12.6 months (range, 3.3-147.6 months). There were $11(19.3 \%)$ patients that underwent both surgery and radiotherapy, $28(49.1 \%)$ that underwent only surgery, 3 (5.3\%) that underwent only radiotherapy, and 15 $(26.3 \%)$ patients that had neither prior surgery or radiotherapy.

Injections were managed without assistance of healthcare staff in $22.8 \%$ of the patients, either with self-injections or administration by close relatives. A total of 19 (33.3\%) patients received pre-surgical treatment. The most frequent pre-surgical treatment was lanreotide by 10 (17.5\%) patients, followed by octreotide by $6(12.3 \%)$ patients, and cabergoline by 3 (5.3\%) patients.

When treatment with lanreotide Autogel was started, 18 patients were receiving pharmacotherapy for acromegaly, 10 (17.5\%) with SSAs (4 lanreotide SR, 4 octreotide LAR, and 2 octreotide), 7 (12.3\%) with dopamine agonists, $1(1.8 \%)$ with $\mathrm{GH}$ receptor antagonists. At initiation of treatment with lanreotide Autogel, median hormonal values were $\mathrm{GH}: 2.6 \mathrm{ng} / \mathrm{ml}$ (range $0.2-48.2$ ) and IGF-I: $1.6 \times$ ULN (range 1.0-4.4); 29 patients had GH levels $\geq 2.5 \mathrm{ng} / \mathrm{ml}$ (47 patients $\geq 1 \mathrm{ng} / \mathrm{ml}$ ) and all patients had non-normalized IGF-I levels.

Concerning signs and symptoms of acromegaly at diagnosis, acral growth was the most frequent, reported by $51(89.5 \%)$ patients, followed by headache in $35(61.4 \%)$ patients and arthralgia in 27 (47.4\%) patients. Median hormonal values at start of lanreotide treatment were $\mathrm{GH}$ : 
Table 2 Hormone data in the PAS population $(N=57)$.

\begin{tabular}{llllll}
\hline & At diagnosis & $\begin{array}{l}\text { Following } \\
\text { presurgical } \\
\text { treatment }\end{array}$ & After surgery & $\begin{array}{l}\text { At start of } \\
\text { lanreotide Autogel } \\
\text { treatment }\end{array}$ & $\begin{array}{l}\text { At hormone } \\
\text { control }^{\mathrm{b}}\end{array}$ \\
\hline $\mathrm{GH}(\mathrm{ng} / \mathrm{ml}), \mathrm{n}^{\mathrm{a}}$ & 54 & 16 & 35 & 53 & 46 \\
Median $($ range $)$ & $8.0(0.2-177.0)$ & $2.0(0.2-63.3)$ & $3.1(0.1-177.0)$ & $2.6(0.2-48.2)$ & $0.83(0.1-5.7)$ \\
IGF-I $\left(\times\right.$ ULN), $n^{\text {a }}$ & 40 & 14 & 32 & 53 & 55 \\
Median $($ range $)$ & $2.2(0.9-5.1)$ & $1.4(0.7-5.2)$ & $1.4(0.2-7.4)$ & $1.6(1.0-4.4)$ & $0.8(0.4-1.5)$ \\
\hline
\end{tabular}

$\mathrm{GH}$, growth hormone; IGF, insulin growth factor; PAS, primary analysis set; ULN, upper limit of normal.

a Number of patients with available information.

b Hormonal normalization on at least 2 different evaluations. Hormonal control was considered to have been achieved at the second evaluation and this timepoint was used for statistical analyses.

$2.6 \mathrm{ng} / \mathrm{ml}$ (range 0.2-48.2) and IGF-I: $1.6 \times$ ULN (range 1.0-4.4).

Mean treatment duration with lanreotide Autogel was 68 months $(95 \% \mathrm{Cl} 55-80)$. At the end of the study period, $47(82.5 \%)$ patients continued with active treatment. Lanreotide Autogel $120 \mathrm{mg}$ was the most common starting dose (29 [51\%] patients). An extended dosing interval (6, 8 and 12 weeks) at lanreotide Autogel initiation was reported in $25(44 \%)$ patients included in the study. Five different subgroups were further analyzed according to starting dosage pattern: $60 \mathrm{mg} / 4$ weeks $(n=13), 90 \mathrm{mg} / 4$ weeks $(n=6), 120 \mathrm{mg} / 4$ weeks $(n=13), 120 \mathrm{mg} / 6$ weeks $(n=6)$, and $120 \mathrm{mg} / 8$ weeks $(n=9)$. Other dosages included: $90 \mathrm{mg} /$ 6 weeks $(n=4), 90 \mathrm{mg} / 8$ weeks $(n=3), 60 \mathrm{mg} / 8$ weeks $(n=2)$ and $120 \mathrm{mg} / 12$ weeks $(n=1)$. Due to the small number of patients, these subgroups were not analyzed separately (Table S1).

\section{Primary endpoint}

The median time to reach hormonal control was 4.9 months (range 1.2-117.0), Fig. 1. The median time to reach hormonal normalization in the $120 \mathrm{mg} / 6$ weeks subgroup $(n=6)$ was 8.2 months (range $2.8-117.0$ ), in the $120 \mathrm{mg} / 4$ weeks subgroup $(n=13)$ was 8.1 months (range $2.2-106.8)$, in the $60 \mathrm{mg} / 4$ weeks subgroup $(n=13)$ was 5.0 months (range 1.2-57.6), in the $120 \mathrm{mg} / 8$ weeks subgroup $(n=9)$ was 4.2 months (range 1.8-22.0), and in the $90 \mathrm{mg} / 4$ weeks subgroup $(n=6)$ was 3.4 months (range 2.6-28.3). More than half of the patients $(n=37,64.9 \%)$ achieved hormonal control in less than 10 months; however, there were 4 patients that took over 3 years to reach hormonal control (Table S2). The median time to reach hormonal control among the 47 patients who were not receiving an SSA when starting treatment with lanreotide Autogel was similar to the overall population (4 months [range, 1-107 months]).

Median hormonal values when hormonal control was achieved were $\mathrm{GH}: 0.83 \mathrm{ng} / \mathrm{ml}$ (range $0.1-5.7$ ) and IGFI: $0.8 \times$ ULN (range 0.4-1.5) (Table 2). The median $\mathrm{GH}$ and IGF-I values in each dosage subgroup were $0.80 \mathrm{ng} / \mathrm{ml}$ (range 0.1-4.3) and 0.9xULN (range 0.4-1.5) in the $60 \mathrm{mg} / 4$ weeks subgroup, $0.50 \mathrm{ng} / \mathrm{ml}$ (range $0.3-2.0$ ) and $0.7 \times$ ULN (range $0.6-1.4$ ) in the $90 \mathrm{mg} / 4$ weeks subgroup, $1.25 \mathrm{ng} / \mathrm{ml}$ (range $0.2-5.7$ ) and $0.8 \times \mathrm{ULN}$ (range $0.4-1.0$ ) in the $120 \mathrm{mg} / 4$ weeks subgroup, $1.93 \mathrm{ng} / \mathrm{ml}$ (range $0.7-4.5$ ) and $0.8 \times$ ULN (range 0.6-1.0) in the $120 \mathrm{mg} / 6$ weeks subgroup, and $0.99 \mathrm{ng} / \mathrm{ml}$ (range $0.4-2.8$ ) and $0.8 \times$ ULN (range $0.5-1.0$ ) in the $120 \mathrm{mg} / 8$ weeks subgroup.

\section{Secondary endpoints}

\section{Use of healthcare resources}

Globally, from the start of treatment until hormone control obtained, the median number of endocrinologist visits was 3 (range 1-64), of hospital nurse visits was 1 (range 0-64), and outpatient nurse visits was 1 (range 0-132).

Overall, the median number of laboratory tests performed was 2.5 (range 1-20) while the median number of imaging tests was 1 (range $0-9$ ). The median number of days of absenteeism overall was 6.5 (range 2-151) days until hormone control was obtained. For the different subgroups, the median number of days of absenteeism was 10 (range $3-151$ ) in the $60 \mathrm{mg} / 4$ weeks subgroup, 8.5 (range 5-20) in the $90 \mathrm{mg} / 4$ weeks subgroup, 13 (range 3-146) in the $120 \mathrm{mg} / 4$ weeks subgroup, 9 (range 2-81) in the $120 \mathrm{mg} / 6$ weeks subgroup, and 6 (range $2-23$ ) in the $120 \mathrm{mg} / 8$ weeks subgroup.

\section{Control of co-morbidities}

Hypertension was reported in 29 (51\%) patients, both at the start of lanreotide Autogel treatment and when hormone control was achieved (28 patients had arterial hypertension at both time points and 1 patient was reported with arterial hypertension at the start of treatment, but not at hormone control and 1 patient did not have arterial hypertension at the start of treatment, but did at hormone control). The daily dose of medication for hypertension was maintained in $17(60.7 \%)$ patients, the active principle was changed for $5(17.9 \%)$ patients, daily dose was increased in 2 (7.1\%) patients, medication was discontinued in 2 (7.1\%) patients, daily dose was reduced in 1 (3.6\%) patient, and the active principle was changed plus the daily dose was increased in 1 


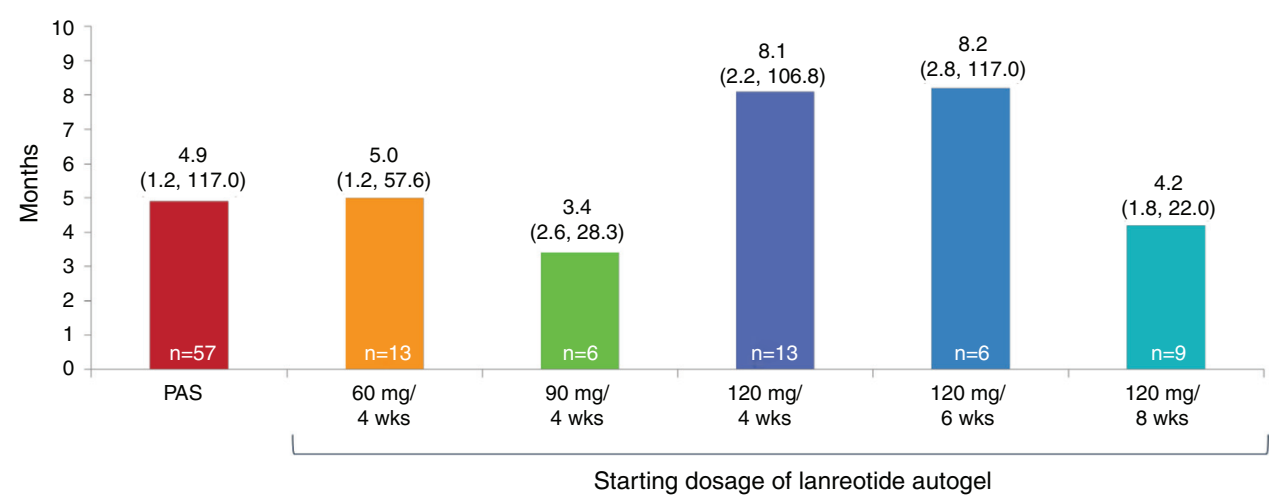

Figure 1 Median time to hormonal control, months (range). The 10 patients with other starting dosages of lanreotide Autogel: $90 \mathrm{mg} / 6$ weeks $(n=4), 90 \mathrm{mg} / 8$ weeks $(n=3), 60 \mathrm{mg} / 8$ weeks $(n=2)$ and $120 \mathrm{mg} / 12$ weeks $(n=1)$, have not been analyzed separately due to the small number of patients in each subgroup. PAS, primary analysis set.

(3.6\%) patient. Information on hypertension medication was missing in 1 patient.

At the start of treatment with lanreotide Autogel 11 (19.6\%) patients had diabetes. When biochemical control of acromegaly was achieved, 16 (28.1\%) patients were reported with diabetes and had a median $\mathrm{HbA1c}$ level of $6.9 \%$ (range 5.5-8.1). The daily dose of diabetes medication was maintained in $7(50.0 \%)$ patients, increased in $3(21.4 \%)$ patients, and reduced $2(14.3 \%)$ patients, finally, the medication was changed in 2 (14.3\%) patients. Information on diabetes medication was missing in 2 patients.

Carpal tunnel syndrome was reported in 5 (8.8\%) patients when lanreotide Autogel treatment was started and when hormone control was reached, it was present in 2 patients (3.5\%). Sleep apnea was reported at the start of treatment in 11 (19.3\%) patients. When hormone control was reached, sleep apnea was reported in 12 (21.1\%) patients. Ten patients of the patients with sleep apnea reported this co-morbidity at both time points (start of treatment and at hormone control). In 1 patient sleep apnea was reported at the start of treatment, but not at hormone control. Two patients did not report sleep apnea at the start of treatment but did at hormone control).

\section{Tumor size}

At diagnosis, 22 (38.6\%) of patients had microadenoma and $35(61.4 \%)$ had macroadenoma (21 with extrasellar extension and 14 intrasellar). There were 19 patients that had information on tumor volume at the beginning of treatment with lanreotide Autogel, the mean maximum tumor volume in these patients was $2010 \mathrm{~mm}^{3}$ (standard deviation [SD] $7801 \mathrm{~mm}^{3}$ ). Only 12 patients had information on tumor volume both at the beginning of lanreotide Autogel and at the last evaluation during treatment with lanreotide Autogel. The mean maximum tumor volume in these 12 patients was $3182 \mathrm{~mm}^{3}$ (SD $38186 \mathrm{~mm}^{3}$ ) at the start of treatment with lanreotide Autogel and was $2218 \mathrm{~mm}^{3}$ (SD $26616 \mathrm{~mm}^{3}$ ) at the most recent evaluation during treatment with lanreotide Autogel. In these 12 patients, there was a mean percentage of tumor reduction of $46.7 \%$ (SD $36.9 \%$ ).

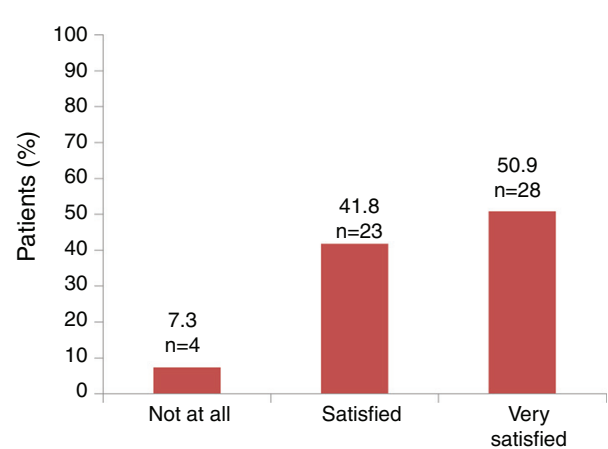

Figure 2 Patient satisfaction with lanreotide Autogel therapy $(n=55){ }^{*}$

*Information was not available for 2 patients.

\section{Satisfaction and adherence}

Globally, 51 out of 55 (92.7\%) patients referred to be satisfied or very satisfied with the lanreotide Autogel treatment (Fig. 2). Only 4 (7.3\%) patients were not at all satisfied with the treatment: one patient in the $90 \mathrm{mg} / 4$ weeks subgroup, one patient in the $120 \mathrm{mg} / 4$ weeks subgroup and 2 patients in the $120 \mathrm{mg} / 8$ weeks subgroup, respectively. Information on "satisfaction"' was not available for 2 patients.

There was good adherence to therapy. Globally 49 (86.0\%) patients declared not to miss any dose during the reporting period. The dose omissions in 8 patients were as follows: 1 dose omitted $(n=2), 1$ or 2 doses omitted $(n=1), 2$ doses omitted $(n=3), 5$ doses omitted $(n=1)$, not specified $(n=1)$. When subgroups were analyzed, compliance to treatment was observed in $92.3 \%$ patients in the $60 \mathrm{mg} / 4$ weeks subgroup, $83.3 \%$ patients in the $90 \mathrm{mg} / 4$ weeks subgroup, $84.6 \%$ patients in the $120 \mathrm{mg} / 4$ weeks subgroup, $66.7 \%$ patients in the $120 \mathrm{mg} / 6$ weeks subgroup and $77.8 \%$ for patients in the $120 \mathrm{mg} / 8$ weeks subgroup.

\section{Discussion}

In a real-life setting, as analyzed in the ACROSTART study, the median time elapsed between initiating treatment with lanreotide Autogel and achieving hormonal control was 4.9 months. Real-life treatment with lanreotide Autogel led 
to a fast hormonal control, with a high treatment adherence and treatment satisfaction, despite disparity of starting doses and interval dosing. Very limited data have been published concerning the dosing of SSAs in routine clinical practice. ${ }^{6,7,10,11}$

In the ACROSTART study, there were 9 different starting dosing regimens in 57 patients, from the most $(120 \mathrm{mg} /$ 4 weeks) to the least $(60 \mathrm{mg} / 8$ weeks) dose intensity, reflecting the disparity of treatment regimens in clinical practice. There did not appear to be a specific pattern explaining the investigator's choice of the initial dose and dosage interval of lanreotide Autogel. Patients might have started lanreotide Autogel treatment with an extended dosing interval if they were previously well controlled with octreotide LAR $20 \mathrm{mg}$ every 4 weeks (q4w) or $30 \mathrm{mg} \mathrm{q} 4 \mathrm{w}$. However, patients who began with lower doses/prolonged dosing intervals of lanreotide Autogel might have had a shorter median time to hormone control achievement and may reflect a postsurgical population with lower initial IGF-I levels or smaller tumors. Additional analyses on patients that started treatment with lanreotide Autogel with an extended dose did not reveal any baseline characteristics that could explain the initial choice of treatment. Gender, age, time since diagnosis and hormonal values at start of treatment were similar. There were slightly more patients with macroadenomas in the group of patients starting with an extended dose $76 \%$ compared with $61 \%$ in the overall population.

SSAs have a well-established profile and patients do not typically discontinue treatment due to AEs. ${ }^{12}$ In patients with acromegaly, the approved starting dose for SSA therapy was determined in pharmacokinetic and pharmacodynamic studies. The initial dosage of lanreotide Autogel can be $60-120 \mathrm{mg}$ administered every 4 weeks followed by adjustment based on GH and/or IGF-I levels. Guidelines recommend increasing the SSA dose in response to the patient's need for additional symptom control or decreasing the dose if the patient has shown signs of improvement. ${ }^{2}$ The dose adjustments recommend maintaining $90 \mathrm{mg} / 4$ weeks if $\mathrm{GH}>1$ to $\leq 2.5 \mathrm{ng} / \mathrm{ml}$, IGF-I normal and clinical symptoms controlled; increasing the dose to $120 \mathrm{mg} / 4$ weeks if $\mathrm{GH}>2.5 \mathrm{ng} / \mathrm{ml}$, IGF-I elevated and/or clinical symptoms uncontrolled; reducing the dose to $60 \mathrm{mg}$ q4w if $\mathrm{GH}$ $\leq 1 \mathrm{ng} / \mathrm{ml}$, IGF-I normal and clinical symptoms controlled; and considering an extended dosing interval of $120 \mathrm{mg} / 6$ or 8 weeks if patients are controlled on $60-90 \mathrm{mg}$ q4w. In the ACROSTART study, the main starting dosing regimens were $60 \mathrm{mg} / 4$ weeks and $120 \mathrm{mg} / 4$ weeks followed by $120 \mathrm{mg} / 8$ weeks. Based on published studies, dose titration of lanreotide appears to improve its efficacy in patients with acromegaly, with many patients requiring escalation to 120 mg/4 weeks. $^{13}$

Using pharmacokinetic model-based simulations, there was support that pharmacologically effective levels of lanreotide can be maintained after extending the dosing interval for lanreotide Autogel beyond the standard 4week dosing interval. ${ }^{14}$ Studies evaluating alternative dosing schemes in patients with acromegaly that was well controlled, prolonging the time interval from 4 to $6 / 8$ weeks between lanreotide Autogel injections did not lead to loss of efficacy. ${ }^{6,9,15,16}$

In the large international clinical trial, Lanreotide Extended Autogel Duration (LEAD), hormonal control was achieved with lanreotide Autogel given at a dose of $120 \mathrm{mg}$ on the extended dosing interval (the first 24 weeks at a 6-week dosing interval with a further 24 weeks at a 6- or 8week dosing interval) in patients with acromegaly who were well controlled with octreotide LAR 10 or $20 \mathrm{mg} / 4$ weeks for $\geq 6$ months. ${ }^{9}$ Three quarters of the patients $(75.8 \%)$ maintained IGF-I control 48 weeks after switching to an extended dosing interval. The use of alternative, extensive dosing regimens may improve adherence to treatment and over time can reduce both direct drug costs and indirect costs such as burden on healthcare resources. ${ }^{9}$ Lanro-Study was an observational, prospective study, that evaluated over 24 months the dosage of lanreotide Autogel $120 \mathrm{mg}$ in routine acromegaly care in Poland. ${ }^{7}$ Patients were eligible for the study eligible if they were treated with lanreotide Autogel $120 \mathrm{mg}$ in routine practice for at least three months. Of the 132 patients analyzed, 69 patients (52\%) received lanreotide Autogel $120 \mathrm{mg} / 4$ weeks and 63 patients (48\%) received lanreotide Autogel $120 \mathrm{mg}$ at a dosing interval $>4$ weeks. The Somatuline Depot for Acromegaly (SODA) was an observational study investigating the use of lanreotide Autogel/Depot in clinical practice in the US. ${ }^{11}$ Patients were eligible for the study if they were treated with lanreotide Autogel/Depot, both patients who were treatment naive and those switched from other agents. Of the 166 patients enrolled in the study, $60 \mathrm{mg}$ was the starting dose for 27 (16\%) patients, $90 \mathrm{mg}$ for 94 (57\%) patients, and $120 \mathrm{mg}$ for 45 (27\%) patients. Almost all patients received injections every 4 weeks, but one patient received $120 \mathrm{mg}$ every $\geq 6$ weeks. Unlike the ACROSTART study, not all patients in the Lanro-Study or the SODA study had achieved hormonal control. In the retrospective analysis of the German Acromegaly Register, of patients with acromegaly in Germany, 407 of the 1344 patients (30.3\%) had received SSAs. ${ }^{10}$ Among patients controlled (normalized IGF-I) by lanreotide depot monotherapy $(n=27)$, the median lanreotide dose was 60 (range $50-120) \mathrm{mg}$ every 4 weeks. Overall, the main starting doses reported in the ACROSTART study in Spain are comparable to what has been reported in clinical practice in Poland, the US, and Germany, despite disparity of starting doses and interval dosing.

In the ACROSTART study, both patient satisfaction (93\%) as well as adherence (86\%) were declared as high by the patient. Although, a limitation regarding the collection of the adherence data was that it was collected from the patients' clinical history. In the ACROSTART study, 22.8\% of the patients managed injections without assistance of healthcare staff, which is higher than has been reported in the real-life study in Poland $(2.6 \%),{ }^{7}$ but lower than the real-life study in the US $(40.4 \%$ at enrollment and $37.9 \%$ at 12 months) ${ }^{11}$; suggesting that in Spain there is a higher opportunity for self-injection. Studies have found an increased preference for self or partner injection over receiving the injection by a healthcare professional. ${ }^{17,18}$ In the SODA study, injection by healthcare staff was considered less convenient than self or partner injection. ${ }^{11}$ Furthermore, achievement of biochemical control after 1 year of lanreotide treatment was significantly greater in patients who exclusively were able to home inject (patient or partner only) compared with patients who received injections by healthcare professionals. ${ }^{11}$ Although it may simply reflect the fact that patients who are better controlled visit the 
physician's office less often; it is also possible that there was a higher adherence among home injectors. Similar or superior treatment adherence with home injection has been reported in other therapeutic indications that require injections that can be administered by healthcare professionals or home injection. ${ }^{19,20}$

There are several limitations in this study, including its retrospective and observational design. An important bias to the study was the inclusion only of patients who responded to treatment. Furthermore, the GH and IGF-I values were obtained from several centers, measured as per clinical practice and had not been previously standardized across all centers. As a reflection of real-life practice, the frequency of study visits, biochemical testing, and radiological evaluation were determined by each treating physician. In addition, the distribution of the sample size into subgroups has not permitted to extensively explore specific outcomes according to initial dosing pattern. However, it is speculative to suggest that prolonged interval injections could increase patient convenience by reducing the number of visits and tests. Additionally, pretreatment with other drugs, including SSAs, may have had an impact on the primary outcomes. Nevertheless, the median time to reach hormonal control among patients who were not receiving an SSA when initiating treatment with lanreotide Autogel was similar to the overall population.

In conclusion, real-life treatment with lanreotide Autogel led to an early hormonal control in responder patients, with a high treatment adherence and treatment satisfaction, despite disparity of starting doses and interval dosing and provides clinical evidence that extending the dosing interval to 42 and 56 days in clinical practice is possible

\section{Funding}

This study was funded by Ipsen Pharma S.A., Spain.

\section{Conflict of interest}

CAE received honoraria from IPSEN, Novartis and Pfizer as speaker fees, has served on an advisory board, received lecture fees and sponsorship for travel and accommodation in international scientific meetings from IPSEN, Novartis and Pfizer.

CBC received honoraria from IPSEN, Novartis, Pfizer, AstraZeneca, Lilly, and Novo Nordisk as speaker fees, and received sponsorship for travel and accommodation in international scientific meetings from IPSEN, Novartis and Pfizer.

MMA has received honoraria as speaker fees, has served on advisory board, received lecture fees and sponsorship for travel and accommodation in international scientific meetings from IPSEN, Novartis and Pfizer.

EMT has received honoraria from IPSEN and Novartis as speaker fees.

JAP has served on an advisory board, received lecture fees and sponsorship for travel and accommodation in international scientific meetings from IPSEN, Novartis, and Pfizer.

EMVM has participated in conferences, courses, and steering committees of clinical studies promoted by IPSEN, Novartis, and Pfizer.
MAGR has received sponsorship from IPSEN for attending medical conferences and meetings.

MPdMN has received honoraria as speaker fees and received sponsorship for travel and accommodation in international scientific meetings/trainings from IPSEN, Novartis, and Pfizer.

IHR has participated in conferences and courses organized by Novartis, Pfizer, IPSEN, and has participated in studies sponsored by Novartis, Pfizer, and IPSEN.

GdICS and AH are IPSEN employees.

EMVM, JAGA, MAGM, ISV, ER, CPF, AMPA do not have conflicts of interest.

\section{Acknowledgments}

The authors thank Francesc Pérez, an Ipsen Pharma employee, for his help during data collection.

Medical writing support was provided by Aurora O'Brate and funded by Ipsen Pharma S.A., Spain.

\section{Appendix A. Supplementary data}

Supplementary data associated with this article can be found, in the online version, at doi:10.1016/j.endinu. 2018.12.004.

\section{References}

1. Reddy R, Hope S, Wass J. Acromegaly. BMJ. 2010;341:c4189.

2. Katznelson L, Laws ER Jr, Melmed S, Molitch ME, Murad MH, Utz A, et al. Acromegaly: an endocrine society clinical practice guideline. J Clin Endocrinol Metab. 2014;99:3933-51.

3. Holdaway IM, Bolland MJ, Gamble GD. A meta-analysis of the effect of lowering serum levels of GH and IGF-I on mortality in acromegaly. Eur J Endocrinol. 2008;159:89-95.

4. Giustina A, Chanson P, Kleinberg D, Bronstein MD, Clemmons DR, Klibanski A, et al. Expert consensus document: a consensus on the medical treatment of acromegaly. Nat Rev Endocrinol. 2014; 10:243-8.

5. Melmed S, Cook D, Schopohl J, Goth MI, Lam KS, Marek J. Rapid and sustained reduction of serum growth hormone and insulinlike growth factor- 1 in patients with acromegaly receiving lanreotide Autogel therapy: a randomized, placebo-controlled, multicenter study with a 52 week open extension. Pituitary. 2010;13:18-28.

6. Schopohl J, Strasburger CJ, Caird D, Badenhoop K, Beuschlein $F$, Droste $M$, et al. Efficacy and acceptability of lanreotide Autogel(R) $120 \mathrm{mg}$ at different dose intervals in patients with acromegaly previously treated with octreotide LAR. Exp Clin Endocrinol Diabetes. 2011;119:156-62.

7. Orlewska E, Kos-Kudla B, Sowinski J, Sworczak K, Zgliczynski W, Lanro-Study G. Dosage and costs of lanreotide Autogel $120 \mathrm{mg}$ administered as part of routine acromegaly care in Poland - two years of data from Lanro-Study. Endokrynol Pol. 2015;66:142-8.

8. Lucas T, Astorga R. Spanish-Portuguese Multicentre Autogel Study Group on Acromegaly Efficacy of Lanreotide Autogel administered every 4-8 weeks in patients with acromegaly previously responsive to lanreotide microparticles 30 mg: a phase III trial. Clin Endocrinol (Oxf). 2006;65:320-6.

9. Neggers SJ, Pronin V, Balcere I, Lee MK, Rozhinskaya L, Bronstein MD, et al. Lanreotide Autogel $120 \mathrm{mg}$ at extended dosing intervals in patients with acromegaly biochemically controlled with octreotide LAR: the LEAD study. Eur J Endocrinol. 2015;173:313-23. 
10. Schofl C, Franz H, Grussendorf M, Honegger J, JaurschHancke C, Mayr B, et al. Long-term outcome in patients with acromegaly: analysis of 1344 patients from the German Acromegaly Register. Eur J Endocrinol. 2013;168:39-47.

11. Salvatori R, Woodmansee WW, Molitch M, Gordon MB, Lomax KG. Lanreotide extended-release aqueous-gel formulation, injected by patient, partner or healthcare provider in patients with acromegaly in the United States: 1-year data from the SODA registry. Pituitary. 2014;17:13-21.

12. Ludlam WH, Anthony L. Safety review: dose optimization of somatostatin analogs in patients with acromegaly and neuroendocrine tumors. Adv Ther. 2011;28:825-41.

13. Carmichael JD. Lanreotide depot deep subcutaneous injection: a new method of delivery and its associated benefits. Patient Prefer Adherence. 2012;6:73-82.

14. Troconiz IF, Cendros JM, Peraire C, Ramis J, Garrido MJ, Boscani PF, et al. Population pharmacokinetic analysis of lanreotide Autogel in healthy subjects: evidence for injection interval of up to 2 months. Clin Pharmacokinet. 2009;48:51-62.

15. Ronchi CL, Boschetti M, Degli Uberti EC, Mariotti S, Grottoli S, Loli P, et al. Efficacy of a slow-release formulation of lanreotide (Autogel) $120 \mathrm{mg}$ in patients with acromegaly previously treated with octreotide long acting release (LAR): an open, multicentre longitudinal study. Clin Endocrinol (Oxf). 2007;67:512-9.

16. Abrams P, Alexopoulou O, Abs R, Maiter D, Verhelst J. Optimalization and cost management of lanreotide-Autogel therapy in acromegaly. Eur J Endocrinol. 2007;157:571-7.

17. Salvatori R, Nachtigall LB, Cook DM, Bonert V, Molitch ME, Blethen S, et al. Effectiveness of self- or partneradministration of an extended-release aqueous-gel formulation of lanreotide in lanreotide-naive patients with acromegaly. Pituitary. 2010;13:115-22.

18. Bevan JS, Newell-Price J, Wass JA, Atkin SL, Bouloux PM, Chapman J, et al. Home administration of lanreotide Autogel by patients with acromegaly, or their partners, is safe and effective. Clin Endocrinol (Oxf). 2008;68:343-9.

19. Zwibel H, Pardo G, Smith S, Denney D, Oleen-Burkey M. A multicenter study of the predictors of adherence to self-injected glatiramer acetate for treatment of relapsing-remitting multiple sclerosis. J Neurol. 2011;258:402-11.

20. Cameron ST, Glasier A, Johnstone A. Pilot study of home selfadministration of subcutaneous depo-medroxyprogesterone acetate for contraception. Contraception. 2012;85: 458-64. 